\title{
Simple Modeling and Simulation of Photovoltaic Panels to Supply Power for Sensor Nodes
}

\author{
Jangwoo Park*, Hong-geun Kim, Yongyun Cho, Changsun Shin and Dongguk \\ Park \\ Department of Information and Communication Engineering, \\ Sunchon National University, 413 Jungangno Suncheon 540-950, Republic of \\ Korea \\ \{jwpark, khg_david,naksu21,lmb, yycho, csshin,dgpark6\}@sunchon.ac.kr
}

\begin{abstract}
This paper introduces the simple method of the mathematical modeling and simulation of current-voltage characteristics for photovoltaic panel. The aim of this modeling is to simply the nonlinear I-V model of photovoltaic panel to easily apply the model to the circuit simulators such as SPICE. So this paper is finding the parameters for the nonlinear I-V equations based on only the data such as open circuit voltage, short circuit current, voltage and current at Maximum power point and temperature coefficient for voltage and current at the nominal condition or the standard test condition which are obtained from manufacturer's datasheet. The model in this paper is simple and has no iteration process during parameter calculation, which makes model complex and time consuming. This model can be suitable and powerful tools for circuit simulator and the modeling and simulation of the MPP tracker including solar panel.
\end{abstract}

Keywords: MPP, Solar panel, Simulation

\section{Introduction}

Standalone operation of sensor networks needs the power source to operate the system. the power sources have to meet the various requirements such as lifetime, size, robustness and etc. Many renewable energy sources have been recently studied such as solar, wind, and waves. Among them, the solar energy has widely used in a lot of systems. To utilize the solar energy, the solar panel should be optimized.

The solar radiation seems to be one of the most promising renewable energy sources and can be directly converted into electricity using the photovoltaic (PV) devices, solar cells. Photovoltaic panels are the fundamental power conversion unit. The output characteristic of the PV panels is nonlinear depending on the irradiation and solar cell temperatures. The PV panels are connected to the configuration and the control algorithms implemented in the switch mode power converters, which are important in the cost effectiveness of a PV plant.

For given environmental conditions, there is Maximum Power Point (MPP), an operating point on the V-I characteristics, where maximum power output is achieved. Therefore, at the MPP the efficiency will be optimized. There are lots of researches about proposing the MPP tracking algorithms and designing the MPP tracker [1-3]. The ability to protect output characteristics of a photovoltaic module is very important for the design of MPP tracking and control strategy. Numerous methods have been proposed for modeling the PV panel and extracting the panel's parameters [4-11]. The performance of the PV panels is evaluated under standard test condition (STC), where an average solar

${ }^{*}$ Corresponding Author 
spectrum at AM1.5 is used [4], the irradiation of $1000 \mathrm{~W} / \mathrm{cm} 2$ and the module temperature of $25 \mathrm{oC}$.

In this paper, a photovoltaic panel modeling method and simulation will be presented. The parameters for the PV model are based on values provided from the manufacturer's datasheet. The proposed model is similar to a single diode model with a series resistance. But the parameters used in proposed model are obtained from only the datasheet measured at STC and the model does not need iteration routine to extract the parameters of I-V characteristics. So, this model is suitable for SPICE modeling and Matlab/Simulink modeling when developing and designing MPPT algorithm. This paper also provides the Simulink modeling of the photovoltaic model performance and some simulation results.

\section{Modeling of Photovoltaic Module}

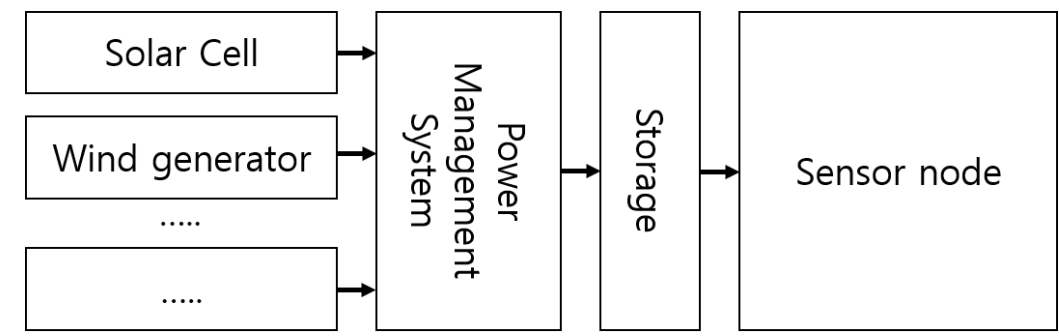

Figure. 1 Sensor Nodes with the Renewable Energy Sources

For Standalone operation, sensor nodes have to have the power system to utilize the renewable energy. There is lots of renewable energy sources recently studied. Among them, recently, solar energy has widely studied and developed. Figure 1 shows the structure of sensor nodes to equipped renewable power sources. In this figure, the system has the ability to get the energy from multi-sources. The energy sources from environment are uncontrolled and very unstable with the time and places so that the power management systems are important. Also, to develop the power management system with the maximum power point tracking, the modeling the energy sources will be need.

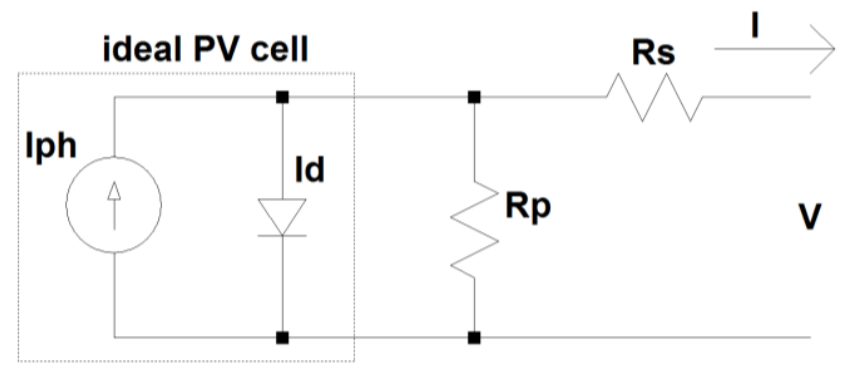

Figure. 2 Equivalent Circuit of a Practical PV Panel Including the Series and Parallel Resistances

The photovoltaic module is a sort of semiconductor diode, whose $\mathrm{p}-\mathrm{n}$ junction is exposed to light. Basically, the PV phenomenon may be described as the absorption of solar radiation. When the energy of the incident photon is sufficient to detach the covalent electrons of the semiconductor, charges are generated. The incidence of light on the cell generates charge carriers that originate an electric current.

The equivalent circuit of a photovoltaic module is represented with ideal PV cell and the series and parallel resistances shown in Figure 2. The basic current-voltage characteristics of the PV module can be expressed $[5,6]$ : 


$$
I=I_{p h}-I_{0}\left[\exp \left(\frac{V+R_{S} I}{V_{T}}\right)-1\right]-\frac{V+R_{S} I}{R_{p}}
$$

where, $I$ and $V$ are the current and voltage of the photovoltaic panel, respectively. $I_{p h}$ $\left(=N_{p} I_{p h, \text { cell }}\right)$ is the photo-generated current in the PV module consisting of $\mathrm{N}_{\mathrm{p}}$ cells connected in parallel. Each cell can generate the photo current of $I_{p h, \text { cell. }} I_{0}\left(=N_{p} I_{0, \text { cell }}\right)$ is the reverse saturation current of the PV module consisting of $N_{p}$ cells connected in parallel where each cell has the reverse saturation current of $I_{0, \text { cell }} . V_{T}\left(=a N_{s} \cdot \mathrm{kT} / \mathrm{q}\right)$ is the thermal voltage of the array with $N_{s}$ cells connected in series where $a(=1.0 \sim 1.5)$ is the ideality factor of the diode, $k(=1.38 e-23 \mathrm{~J} / K)$ is the Boltzmann's constant, $q(=1.602 e-19 C)$ is the electronic charge and $T$ is temperature of the array in Kelvin. $R_{s}$ is the equivalent series resistance of the PV array. $R_{p}$ is the equivalent parallel resistance of the PV array.

The practical PV device is operating in a hybrid behavior of current or voltage source depending on the operating point. In the practical PV device, series resistance R_s has strong influence on the performance of PV module when the device operates in the voltage source region, and influence of a parallel resistance $R_{p}$ will be stronger in the current source region of operation [6]. The value of $R_{p}$ is generally so high that some authors neglect this resistance to simplify the model $[4,7,8]$. The value of $R_{s}$ is very low, and sometimes can be neglected too $[9,10]$.

The photovoltaic array's temperature may be influenced by the solar irradiation and ambient wind speed [11]

$$
\mathrm{T}=3.12+0.25 \frac{\mathrm{s}}{\mathrm{s}_{\mathrm{n}}}+0.899 \mathrm{~T}_{\mathrm{a}}-1.3 \mathrm{v}_{\mathrm{a}}+273
$$

where $S$ and $S_{n}\left(=1000 \mathrm{~W} / \mathrm{m}^{2}\right)$ are the solar irradiation at operating condition and the nominal test condition, respectively, and $T_{a}$ is the ambient temperature and $v_{a}$ is the local wind speed. Equation (2) shows the PV pannel's temperature will be influenced by the solar irradiation and the wind velocity.

The I-V characteristics of the PV devices depend on the internal characteristics of the device $\left(R_{s}, R_{p}\right)$ and on the external influences such as irradiation level and ambient temperature. The incident light is generating the photo current, which depends linearly on the solar irradiation and is influenced by the temperature $[5,6]$ :

$$
I_{p h}=\left(I_{p h, n}+\alpha_{I} \Delta T\right) \frac{s}{s_{n}}
$$

where $I_{p h, n}$ is the light generated current at STC and $\Delta T=T-T_{n}, T$ is the panel temperature irradiation, and $T_{n}$ is the nominal temperature. Because the photo-current is difficult to determine and practically the parallel resistance is high and the series resistance is very small, the assumption $I_{s c} \approx I_{p h}$ is generally used in modeling PV devices.

The open circuit voltage is assumed to be influenced by temperature [7] like

$$
V_{o c}=V_{o c, n}\left(1+\alpha_{V} \Delta T\right)+V_{T} \ln \left(\frac{s}{s_{n}}\right)
$$

where $V_{o c, n}$ is the open circuit voltage measured at the nominal condition and $\alpha_{V}$ is the voltage-temperature coefficient. The datasheets of PV arrays provide a few experimental data about electrical and thermal characteristics. The experimental data from the datasheets are not suitable for I-V curve of PV array such as equation (1). All PV array datasheets give basically the following information: the nominal open-circuit $\operatorname{voltage}\left(V_{o c, n}\right)$, the nominal short-circuit current $\left(I_{s c, n}\right)$, the Maximum Power Point (MPP) $\operatorname{voltage}\left(V_{m p}\right)$, the MPP current $\left(I_{m p p}\right)$, the short-circuit current/temperature coefficient $\left(\alpha_{I}\right)$, the open-circuit voltage/temperature coefficient $\left(\alpha_{V}\right)$, and the experimental peak power $\left(P_{\max }\right)$, which are measured at the nominal condition or standard test conditions(STC) of temperature $T=298 \mathrm{~K}$ and solar irradiation of $\mathrm{S}=1000 \mathrm{~W} / \mathrm{m}^{2}$. At the STC, the basic equation can be rewritten as

$$
I=I_{p h, n}-I_{0, n}\left[\exp \left(\frac{V+R_{S} I}{V_{T, n}}\right)-1\right]-\frac{V+R_{S} I}{R_{p}}
$$

where the subscript $\mathrm{n}$ is used to show the fact the values are measured at the STC. It also be assumed that the series resistance and the parallel resistance are independent of the temperature or solar irradiation. Therefore these parameters don't have a subscript $n$. 
To simplify the modeling, we further assume the parallel resistance $R_{p}$ is so large to ignore the third term of eq. (5).

$$
\mathrm{I}=\mathrm{I}_{\mathrm{ph}, \mathrm{n}}-\mathrm{I}_{0, \mathrm{n}}\left[\exp \left(\frac{\mathrm{V}+\mathrm{R}_{\mathrm{S}} \mathrm{I}}{\mathrm{V}_{\mathrm{T}, \mathrm{n}}}\right)-1\right]
$$

The I-V curve of solar cells has three important points: short $\operatorname{circuit}\left(0, I_{s c}\right)$, open $\operatorname{circuit}\left(V_{o c, 0}\right)$ and maximum power point $\left(V_{m p}, I_{m p p}\right)$. At these important points, the equations are:

$$
\begin{array}{r}
I_{s c, n}=I_{p h, n}-I_{0, n}\left[\exp \left(\frac{R_{s} I_{s c, n}}{V_{T, n}}\right)-1\right] \\
0=I_{p h, n}-I_{0, n}\left[\exp \left(\frac{V_{o c, n}}{V_{T, n}}\right)-1\right] \\
I_{m p p, n}=I_{p h, n}-I_{0, n}\left[\exp \left(\frac{V_{m p p, n}+R_{s} I_{m p p, n}}{V_{T, n}}\right)-1\right]
\end{array}
$$

The diode saturation current may be expressed in its dependence on the temperature [6],

$$
I_{0}=I_{0 . n}\left(\frac{T_{n}}{T}\right)^{3} \exp \left\{\frac{\mathrm{qE}_{G}}{a k}\left(\frac{1}{T_{n}}-\frac{1}{T}\right)\right\}
$$

where $E_{G}$ is the band-gap energy of the PV material. From eq. (8), the diode saturation current at the STC is related to the pho-current at STC,

$$
I_{0, n}=\frac{I_{p h, n}}{\left[\exp \left(\frac{V_{0 c, n}}{V_{T, n}}\right)-1\right]}
$$

The PV model can be improved [6] if (8) is replaced by

$$
I_{0}=\frac{I_{s c, n}+\alpha_{I} \Delta T}{\exp \left(\left(V_{o c, n}+\alpha_{V} \Delta T\right) / V_{T}\right)-1}
$$

With assumption of $V_{o c, n} / V_{T, n} \gg 1, I_{0, n}$ can be reduced as follow:

$$
I_{0, n}=I_{p h, n} \exp \left(-\frac{V_{o c, n}}{V_{T, n}}\right)
$$

From eq. (13) and eq. (6), we can calculate

$$
V=V_{T, n} \ln \left(1+\frac{I_{p h, n}-I}{I_{0, n}}\right)-R_{S} I
$$

Equation (6) can be further manipulated with assuming $\exp \left(\left(V+R_{s} I\right) / V T, n\right) \gg 1$ and eq.

$$
V=V_{o c, n}+V_{T, n} \ln \left(1-\frac{I}{I_{p h, n}}\right)-R_{S} I
$$

Equation (15) is a simple PV model, which is shown in Figure 2 [7]. The diode of Figure 3 has the reverse saturation current of $I_{p h, n}$ and the thermal voltage of $V_{T, n}$.

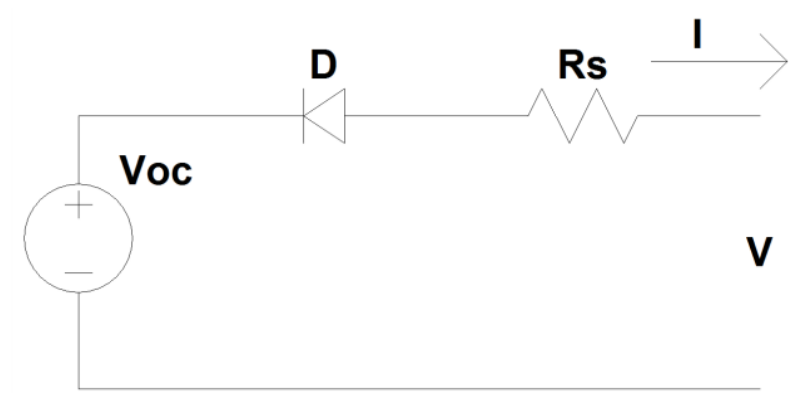

Figure. 3 Equivalent Circuit Obtained from eq (15)

At MPP, eq. (15) will be expressed as:

$$
V_{m p p, n}-V_{o c, n}=V_{T, n} \ln \left(1-\frac{I_{m p p, n}}{I_{p h, n}}\right)-R_{S} I_{m p p, n}
$$


On the other hand, at MPP, the derivative of the power with the current will be zero,

$$
\left.\frac{d P}{d I}\right|_{m p p}=\left.\frac{d(V I)}{d I}\right|_{m p p}=V_{m p p}+\left.I_{m p p} \frac{d V}{d I}\right|_{m p p}=0
$$

And

$$
V=V_{o c, n}+V_{T, n} \ln \left(1-\frac{I}{I_{p h, n}}\right)-R_{S} I
$$

So, from these equations we can obtain

$$
V=V_{o c, n}+V_{T, n} \ln \left(1-\frac{I}{I_{p h, n}}\right)-R_{S} I
$$

Solving eq. (16) and (19), we can get the parameters in the photovoltaic model

$$
\begin{gathered}
V_{T, n}=\frac{\left(2 V_{m p p, n}-V_{o c, n}\right)}{\ln \left(\frac{I_{s c, n}-I_{m p p, n}}{I_{s c, n}}\right)+\frac{I_{m p p, n}}{I_{I c, n}-I_{m p p, n}}} \\
R_{S}=\frac{V_{m p p, n}}{I_{m p p, n}}-\frac{V_{T, n} I_{m p p, n}}{I_{s c, n}-I_{m p p, n}}
\end{gathered}
$$

The series resistance is assumed to be independent on the cell temperature but thermal voltage is depending on the panel temperature so that the thermal voltage at the panel temperature $T$ can be calculated as:

$$
V_{T}=V_{T, n} \frac{T}{T_{n}}
$$

where $V_{T, n}$ is the thermal voltage of the module at the standard temperature and $T_{n}=298 \mathrm{~K}$ is the cell temperature at STC.

\section{Simulink Modeling and Simulation}

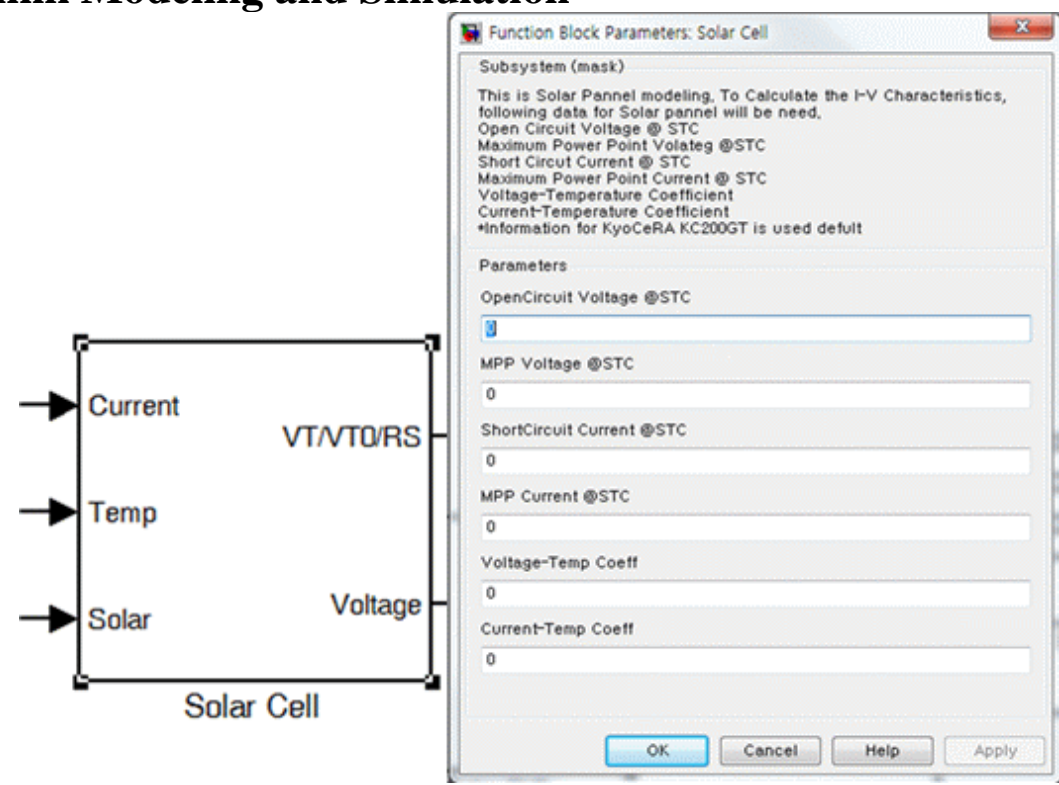

Figure. 4 Topmost Mask of Solar Module Implemented in Simulink

The model of PV panel is implemented with Matlab/Simulink. In Figure 3, the topmost mask of the presented model is shown. Its input is the ambient conditions like ambient temperature and solar irradiation and its output will be the panel current-voltage characteristics and panel parameters (the thermal voltage and the series resistance). This model needs the parameters from the manufacturer's datasheet measured under standard test condition, such as open circuit voltage, maximum power point voltage voltagetemperature coefficient, short circuit current, maximum power point current and the current-temperature coefficient at STC. 


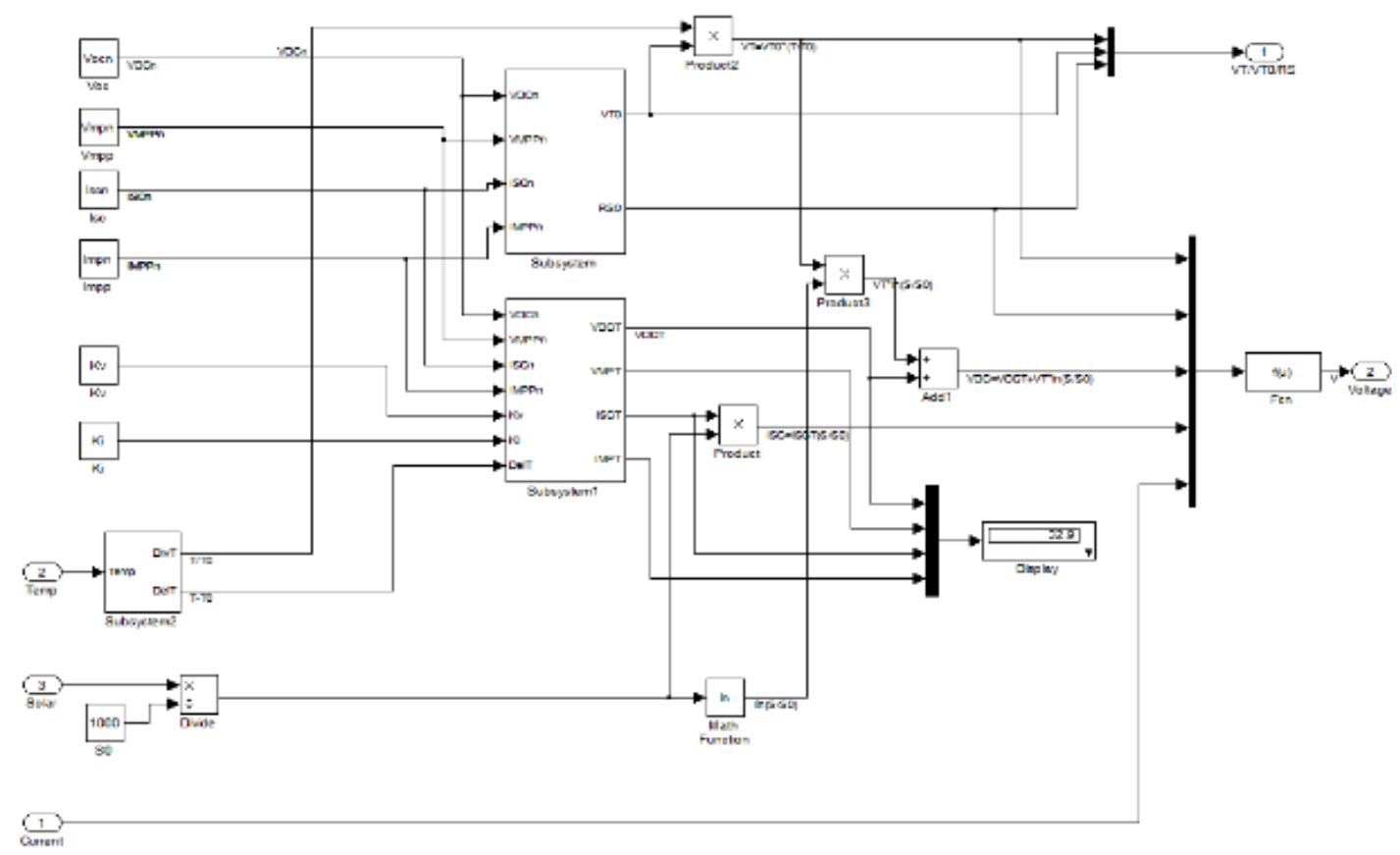

Figure 5. Solar Cell Modeling with Simulink/Matlab

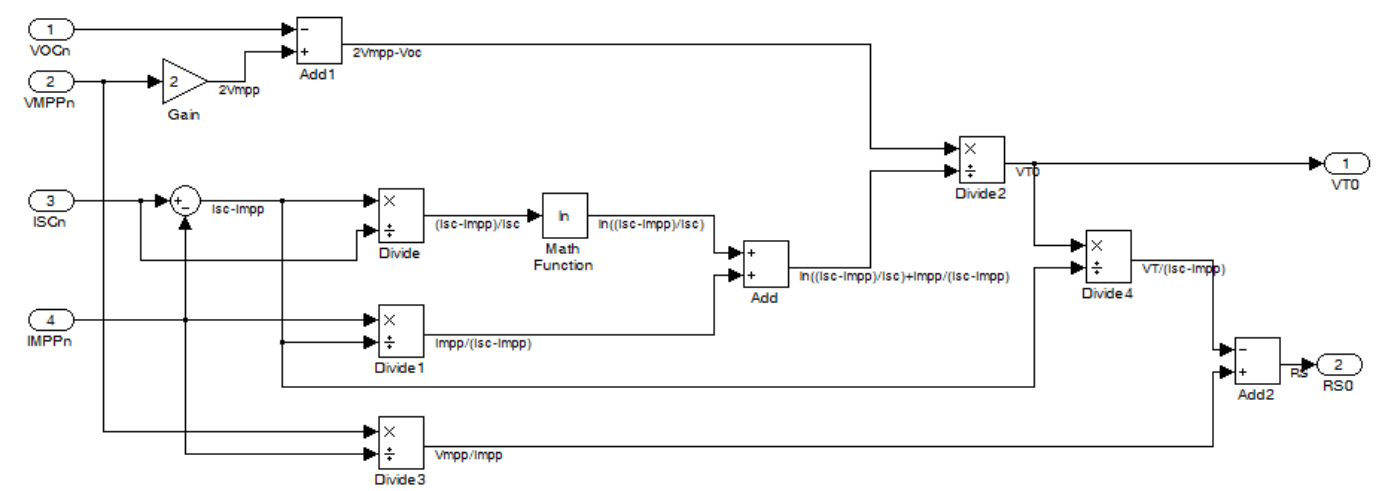

Figure 6. Subblock for the Termal Voltage $\left(V_{T, n}\right)$ at STC and Series Resistance $\left(R_{S}\right)$

Figure 5 is the detailed diagram of the PV module model. This diagram has two subblocks, one is for calculating the thermal voltage and the series resistance at STC and the other is for parameters compensating with the panel temperature and solar irradiation. Figure 6 is showing the more detailed explanation of the thermal voltage and the series resistance at STC. 


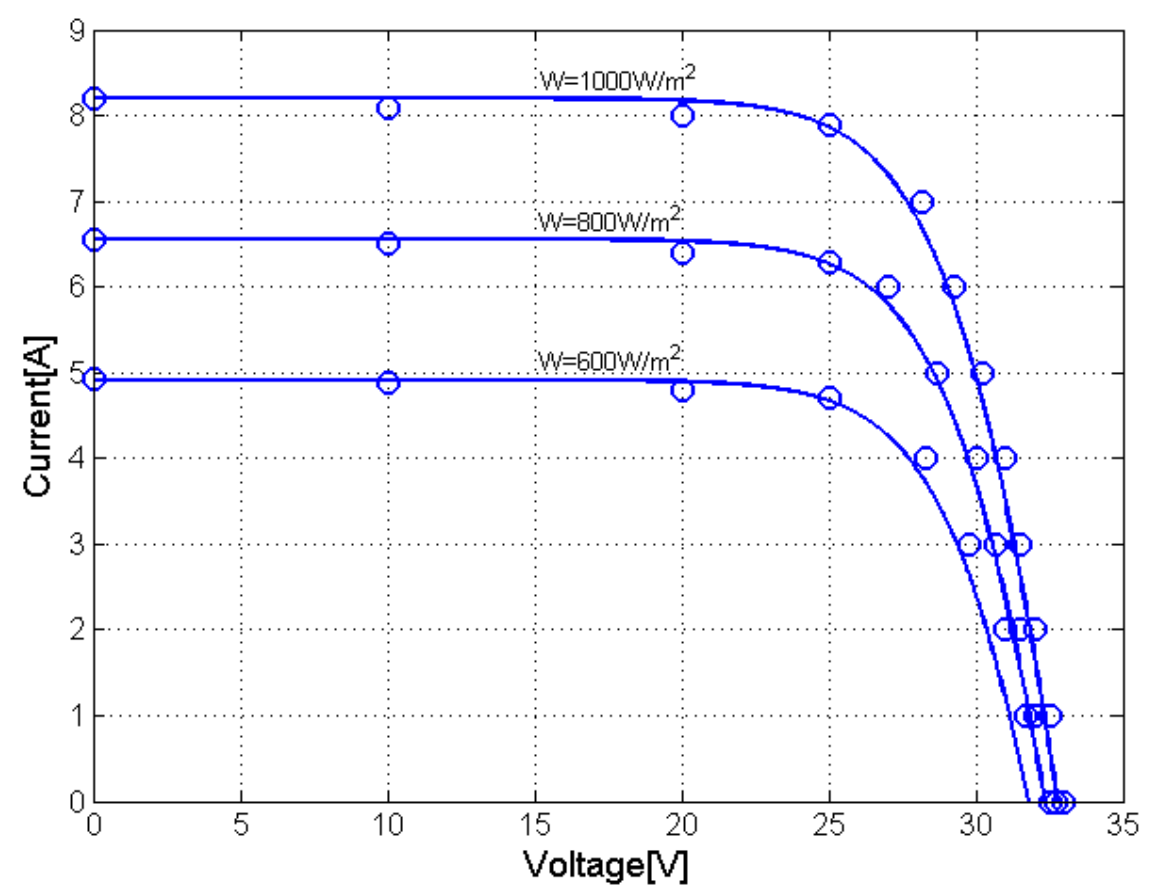

Figure 7. The I-V Characteristics and Experimental Data of the KC200GT at Array Ambient Temperature of $25^{\circ} \mathrm{C}$

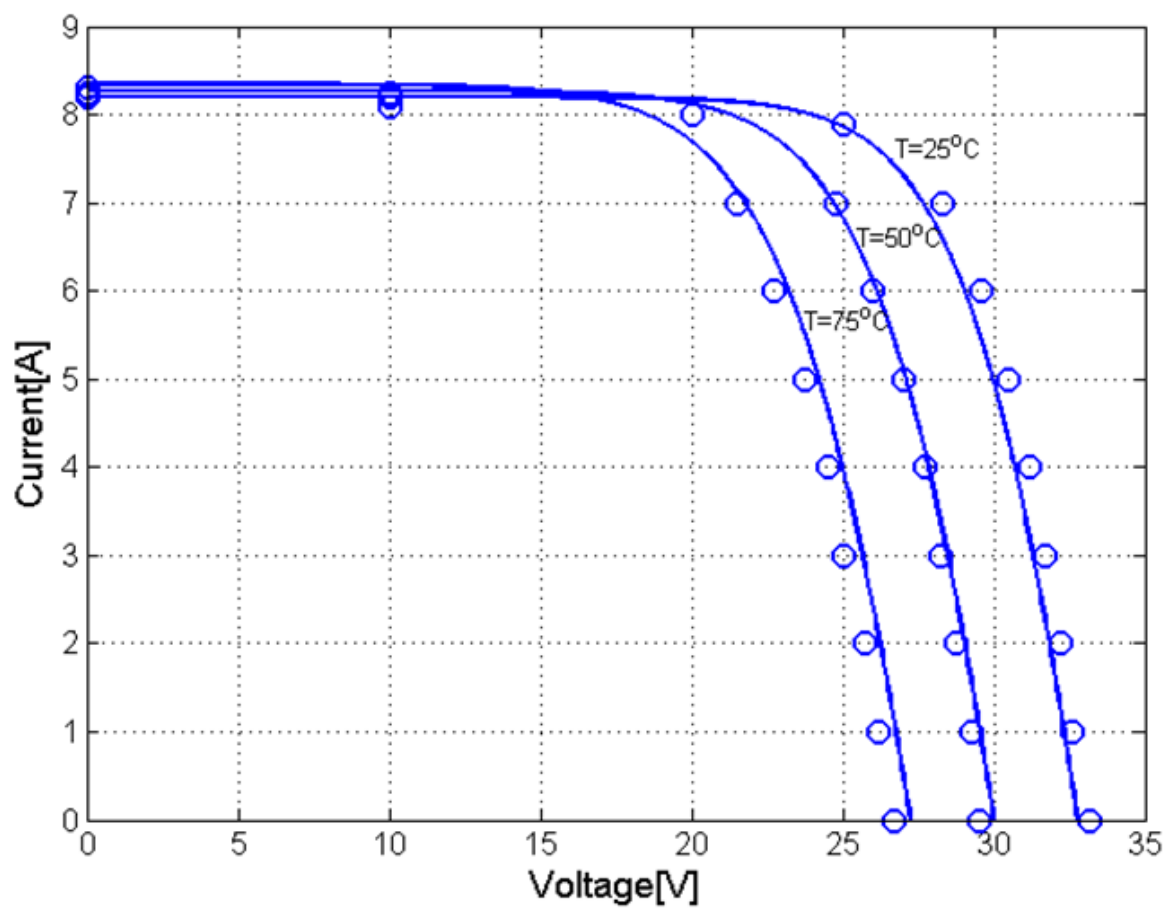

Figure 8. The I-V Characteristics and Experimental Data of the KC200GT at Solar Irradiation of $1000 \mathrm{~W} / \mathrm{m}^{2}$

In order to show the validity of the model, a comparison with other experimental data is very useful. In Figure 7, the I-V characteristics of the photovoltaic panel, KC200GT from KYOCERA [12], are shown where comparing the calculated results with the experimental ones at the temperature of $25^{\circ} \mathrm{C}$. In this figure, the solid line is representing the calculated results and circles are the experimental data. 
Figure 8 shows the temperature dependence of the solar array. In this figure, experimental results are also drawn together. As shown in Figures, simulated results are very close to experimental data but does not show perfect match. However, this model does not need the iteration to find the parameters, which can make the modeling tough and time consuming. That means our model is suitable for simulating the photovoltaic panel. The parameters of the KC200GT solar array at the nominal condition are shown in Table 1.

Table 1. Parameter of KC200GT Solar Array at STC

\begin{tabular}{l|c|l}
\hline Open circuit voltage & $V_{o c, n}$ & $32.9 \mathrm{~V}$ \\
\hline Voltage at MPP & $V_{m p p, n}$ & $26.3 \mathrm{~V}$ \\
\hline Short Circuit Current & $I_{s c, n}$ & $8.21 \mathrm{~A}$ \\
\hline Current at MPP & $I_{m p p, n}$ & $7.61 \mathrm{~A}$ \\
\hline Voltage-Temperature Coef. & $\alpha_{V}$ & $-0.123 \mathrm{~V} / \mathrm{K}$ \\
\hline Current-Temperature Coef. & $\alpha_{I}$ & $0.0032 \mathrm{~A} / \mathrm{K}$ \\
\hline Maximum Power, exp & $P_{\max , e}$ & $200.143 \mathrm{~W}$ \\
\hline
\end{tabular}

\section{Conclusion}

Sensor nodes with characteristics of self-sustainable operation should need the renewable energy sources. Among many environmental energy sources, solar energy is widely used in many systems. The renewable energy such as solar is very unstable so that the power management systems are very essential. To study the power management system including maximum power point tracking, the modeling the devices to convert the environment energy to electrical energy are needed. In this paper, the mathematical modeling of photovoltaic panel is developed. The purpose of this modeling is to simply the mathematical I-V model of photovoltaic panel to easily apply the model to the circuit simulators such as SPICE. The proposed model uses only the data such as open circuit voltage, short circuit current, voltage and current at Maximum power point and temperature coefficient for voltage and current obtained from manufacturer's datasheet at the nominal condition or the standard test condition. The model in this paper is very simple and has no iteration process, which makes model complex and time consuming. This model can be suitable for circuit simulator and the modeling and simulation of the MPP tracker including solar pannel. In this paper, we also introduce the Matlab/Simulink model and simulated results of the solar panel based on the model. The results from simulation are compared with the experimental results to show the validity of our model.

\section{Acknowledgement}

This work was supported by the National Research Foundation of Korea (NRF) grant funded by the Korea government. (MEST) (No. 2012-0003026).

This paper is a revised and expanded version of a paper entitled [Simple Modeling and Simulation of Photovoltaic Panels Using MatlabSimulink] presented at [SIP, China, 2014]. 


\section{References}

[1]. T. Esram and P. L. Chapman, "Comparison of photovoltaic array maximum power point tracking techniques," IEEE Trans. Energy Convers., vol. 22, no. 2, (2007) June, pp. 439-449.

[2]. N. Femia, G. Petrone, G. Spagnuolo and M. Vitelli, "Optimization of perturb and observe maximum power point tracking method," IEEE Trans. Power Electron., vol. 20, no. 4, (2005) July, pp. 963-973.

[3]. V. Salas, E. Olìas, A. Barrado and A. Làzaro, "Review of the maximum power point tracking algorithms for stand-alone photovoltaic systems," Solar Energy Mater. Solar Cells, vol. 90, no. 11, (2006) January, pp. $1555-1578$.

[4]. W. Xiao, W. G. Dunford and A. Capal, "A Novel Modeling Method for Photovoltaic Cells," 35th Annula IEEE Power Electronics Specialists Conference, Aachen, Germany, (2004), pp.1950-1956.

[5]. W. De Soto, S. A. Klein and W. A. Beckman, "Improvement and validation of a model for photovoltaic array performance," Solar Energy, vol. 80, no. 1, (2006) January, pp. 78-88.

[6]. M. G. Villalva, J. R. Gazoli and E. R. Filho," Comprehensive Approach to Modeling and Simulation of Photovoltaic Arrays, IEEE Transactions on Power Electronics, vol. 24, no. 5, (2009) May, pp. 1198-1208.

[7]. L. Cristaldi, M. Faifer, M. Rossi and S. Toscani, "An Improved Model-Based Maximum Power Point Tracker for Photovoltaic Panels," IEEE Transactions on Instrumentation and Measurement, vol. 63, no. 1, (2014) January, pp. 63-71.

[8]. A. N. Celik and N. Acikgoz, "Modelling and experimental verification of the operating current of monocrystalline photovoltaic modules using four- and five-parameter models," Appl. Energy, vol. 84, no. 1, (2007) January, pp. 1-15.

[9]. Y. T. Tan, D. S. Kirschen and N. Jenkins, "A model of PV generation suitable for stability analysis," IEEE Trans. Energy Convers., vol. 19, no. 4, (2004) December, pp. 748-755.

[10].N. D. Benavides and P. L. Chapman, "Modeling the effect of voltage ripple on the power output of photovoltaic modules," IEEE Trans. Ind. Electron., vol. 55, no. 7, (2008) July, pp. 2638-2643.

[11].C. Qi and Z. Ming, "Photovoltaic Module Simulink Model for a Stand-alone PV System," 2012 International Conference on Applied Physics and Industrial Engineering, Physics Procedia, vol. 24, (2012), pp. 94-100.

[12]. “KC200GT High Efficiency Multicrystal Photovoltaic Module Datasheet Kyocera”, [Online]. Available: http://www.kyocerasolar.com/assets/001/5195.pdf. 
International Journal of Control and Automation Vol. 8, No. 2 (2015) 